\title{
La Crisis de los Países del GRAN y la Globalización
}

\author{
Dra. Beatriz Herrera Garcia \\ Directora del Instituto de \\ Investigaciones de la Facultad de \\ Ciencias Contables
}

1. TENDENCIAS DE LA ECONOMIA MUNDIAL

En los últimos tiempos la economia internacional ha experimentado profundas mutaciones en los campos de la producción, comercio, transporte, transferencia de tecnología y movimiento de capitales.

Durante 1992, 1993 y 1994 las principales economias industrializadas han registrado tasas de crecimiento muy modestas. La recuperación de la economía norteamericana se torna lenta, las dificultades de la reunificación alemana impiden que Europa sustituyera a los Estados Unidos como "locomotora" de la economía mundial, y la economía japonesa experimentaba una recesión sin precedentes en la postguerra.

Todo lo anterior ocurría en un ambiente de acentuada globalización. Para América Latina en general, y para el Grupo Andino (GRAN) en particular, los mercados predominantes para las exportaciones se sitúan en el mundo industrializado. Por ello, la tasas de crecimiento de estos países revisten suma importancia, pues determinan el grueso de la demanda de exportaciones subregionales, la relación de intercambio y el grado de proteccionismo.

La década de los ochenta se caracterizó, en la subregión andina, por las políticas de ajuste adoptadas para hacer frente a la restricción externa. La reorientación de las políticas económicas incluía drásticas reformas comerciales y elevado costo social. Sin embargo, la mayoría de países miembros del GRAN ha conseguido incrementar sus coeficientes de exportaciones.
En general, la subregión andina sufrió una gradual transformación de la estructura productiva, hecho que se refleja en el mayor coeficiente entre las exportaciones y el producto del GRAN, así como en la diversificación de las mismas, en aumentos de la competitividad de un número creciente de empresas y en una mejoría en la capacidad empresarial para explotar los mercados externos y acceder a ellos.

2. GRAN, EXPORTACIONES Y CRECIMIENTO

En definitiva ha sido baja la

\section{Cuadro 1}

GRUPO ANDINO: Ritmo de Crecimiento de las Exportaclones y del PBI 1971-1992

(Tasas anuales obtenidas por regresión, porcentajes)

\begin{tabular}{|c|c|c|c|}
\hline \multirow[b]{2}{*}{ PAIS } & \multirow{2}{*}{$\begin{array}{l}\text { PRODUCTO } \\
\text { BRUTO } \\
\text { INTERNO }\end{array}$} & \multicolumn{2}{|c|}{ EXPORTACIONES } \\
\hline & & VOLUMEN & $\begin{array}{l}\text { PODER DE } \\
\text { COMPRA }\end{array}$ \\
\hline Bolivia & 1.2 & -2.4 & 0.6 \\
\hline Colombia & 4.2 & 5.1 & 5.0 \\
\hline Ecuador & 4.5 & 6.7 & 5.3 \\
\hline Perú & 1.3 & 0.6 & 0.0 \\
\hline Venezuela & 1.0 & -2.2 & 1.6 \\
\hline
\end{tabular}


Cuadro 2

\section{GRUPO ANDINO: Crecimiento del Producto y de las Exportaciones}

(US\$ de 1990: Tasas promedio variación anual) (Exportaciones de bienes y servicios)

\begin{tabular}{|l|r|r|r|r|r|c|}
\hline \multirow{2}{*}{\multicolumn{1}{c|}{ PAIS }} & \multicolumn{2}{|c|}{$1980-1985$} & \multicolumn{2}{c|}{$1985-1992$} & \multicolumn{2}{c|}{$1980-1992$} \\
\cline { 2 - 7 } & \multicolumn{1}{c|}{ PIB } & EXPORT & \multicolumn{1}{c|}{ PIB } & EXPOR & \multicolumn{1}{c|}{ PIB } & EXPORT \\
\hline Bolivia & -1.8 & -6.4 & 2.5 & 5.6 & 0.7 & 0.4 \\
\hline Colombia & 2.5 & -1.3 & 4.2 & 11.3 & 3.5 & 5.9 \\
\hline Ecuador & 2.0 & 6.6 & 2.3 & 6.5 & 2.2 & 6.5 \\
\hline Perú & -0.2 & 0.5 & -1.6 & -5.2 & -1.0 & -2.8 \\
\hline Venezuela & -2.0 & -3.9 & 4.4 & 6.1 & 1.7 & 1.8 \\
\hline
\end{tabular}

Fuente: JUNAC y SELA, 1993

relación que ha existido entre la expansión de las exportaciones y el crecimiento económico global de la subregión andina durante los decenios de 1970 y 1980 . (Ver cuadro 1). El vínculo ya débil en la primera década entre ambas variables, se debilitó aún más durante la crisis de los años ochenta, cuando, por un lado, la recesión afectó el nivel de actividad interno $y$, por otro lado, la necesidad del ajuste externo dió impulso al crecimiento de las exportaciones.

Según el Cuadro 2, la relación entre estas dos variables macroeconómicas (exportaciones/producto bruto interno) ha sido muy baja y débil en el caso de los países andinos Bolivia, Perú y Venezuela.

Entre 1980 y 1992, los países de la subregión tuvieron comportamientos disímiles en el incremento de las exportaciones de bienes y servicios. Los países con mejor registro y desempeño exportador fueron Colombia $y$ Ecuador, cuyo volumen de exportaciones creció más que el promedio del GRAN. (Ver, cuadro 2).
En la primera mitad del decenio, se destacó por su desempeño exportadorsólo Ecuador, pero a partir de 1985 el dinamismo de las exportaciones se presentaron en casi todos los países, con la sola excepción de Perú. Bolivia, Colombia, Ecuador y Venezuela expandieron el volumen de sus exportaciones a ritmos mayores que el promedio de la subregión andina.

En el cuadro 2 aparece, en cambio, Perú registrando un retroceso en relación al período anterior obteniendo una tasa negativa $(-5.2 \%)$.

EL período 1980-1985 fue de recesión o lento crecimiento en los países del GRAN, al igual que en todo América Latina, en virtud de los ajustes de la demanda interna efectuados para hacer frente a las restricciones externas derivadas de la crisis de la deuda y a la necesidad de procurar la estabilidad económica. El dinamismo de las exportaciones en Ecuador y Perú, poco pudo incidir para contrarrestar los efectos de estos ajustes sobre el nivel de actividad económica.

En el período 1985-1992 tuvo lugar una recuperación gradual y vacilante el crecimiento del producto en la subregión. (Ver, cuadro 2). Todos los países miembros con la sola excepción de Perú registraron aumentos en su tasa media de variación del PIB.

Por otra parte, la expansión del poder de compra de las exportaciones ha sido en los casos de Bolivia y Venezuela mayor a la de su volumen. En cambio, en los casos de Colombia, Ecuadory Perú ha sido inferior a la de su volumen. Esto último refleja la tendencia al deterioro de los términos de intercambio, ya sea por el retroceso relativo de los precios de las exportaciones o por cambios en la composición de

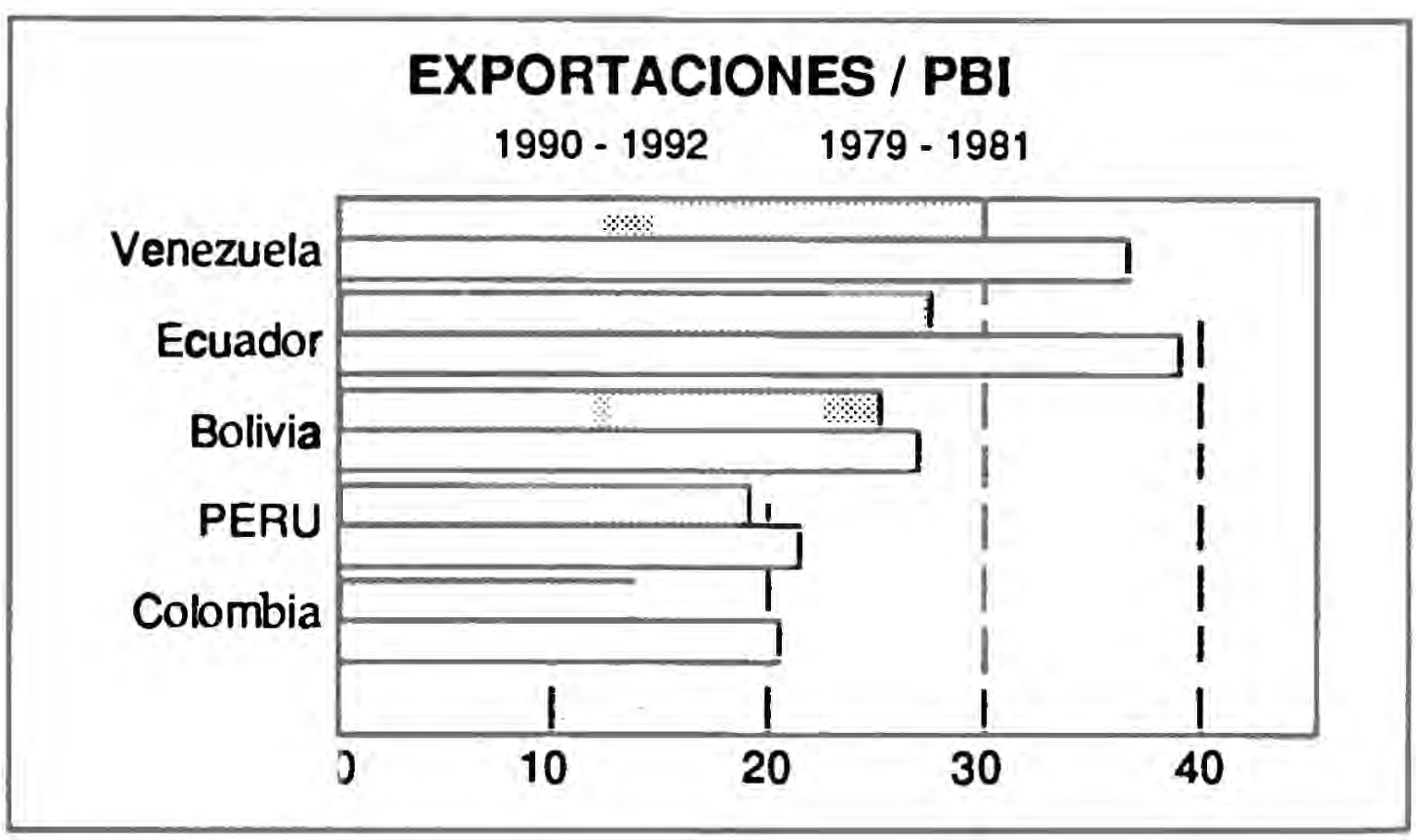




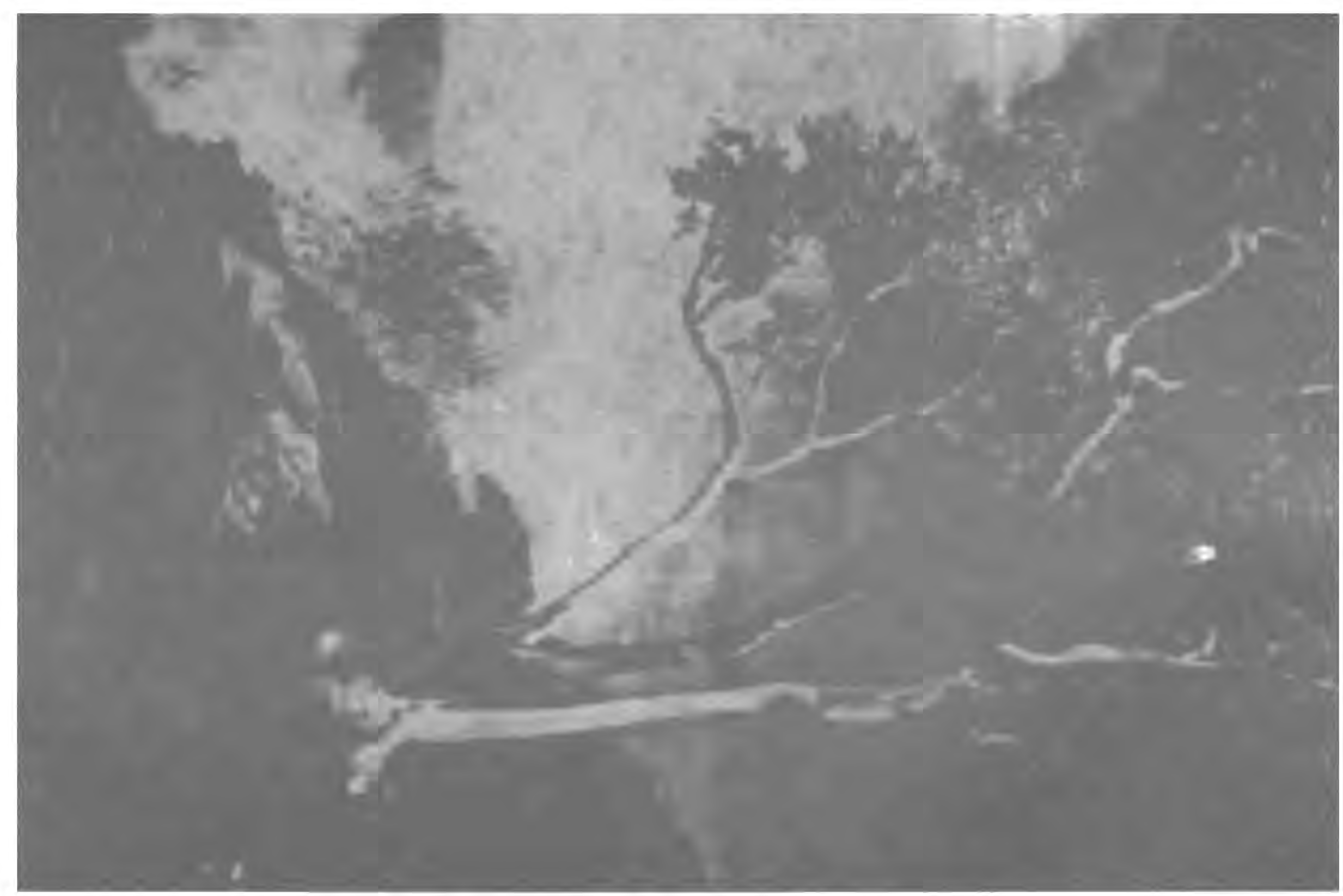

éstas en favor de rubros menos dinámicos, o precios inferiores en el comercio internacional.

3. CAMBIOS EN LA RELACION ENTRE LAS EXPORTACIONES DE BIENES Y SERVICIOS Y EL PRODUCTO INTERNO BRUTO.

En los años ochenta, los países de la subregión andina modificaron su estrategia de desarrollo en armonía con las tendencias mundiales de globalización económica. Ello se refleja en los cambios registrados por los respectivos coeficientes de apertura exportadora.

En el gráfico siguiente se relacionan dos períodos comparativos en base a los coeficientes Exportaciones/PIB. Los aumentos más acentuados cercanos al 40 por ciento del coeficiente, $y$ por tanto, de la orientación exportadora entre 1980 y 1992 han correspondido a Ecuador y Venezuela, quedando rezagados en ese esfuerzo Colombia, Perú y Bolivia cuyos coeficientes constituían siendo internacionalmente bajas (en promedio esa cifra se situaba en $30 \%$ o más del producto).
4. EVOLUCION SECTORIAL DE LAS EXPORTACIONES

Durante los años ochenta el volumen de las exportacionesclasificadas aumentaron según países miembros del GRAN. (Ver cuadro 3 ).

Durante la década de 1970 el

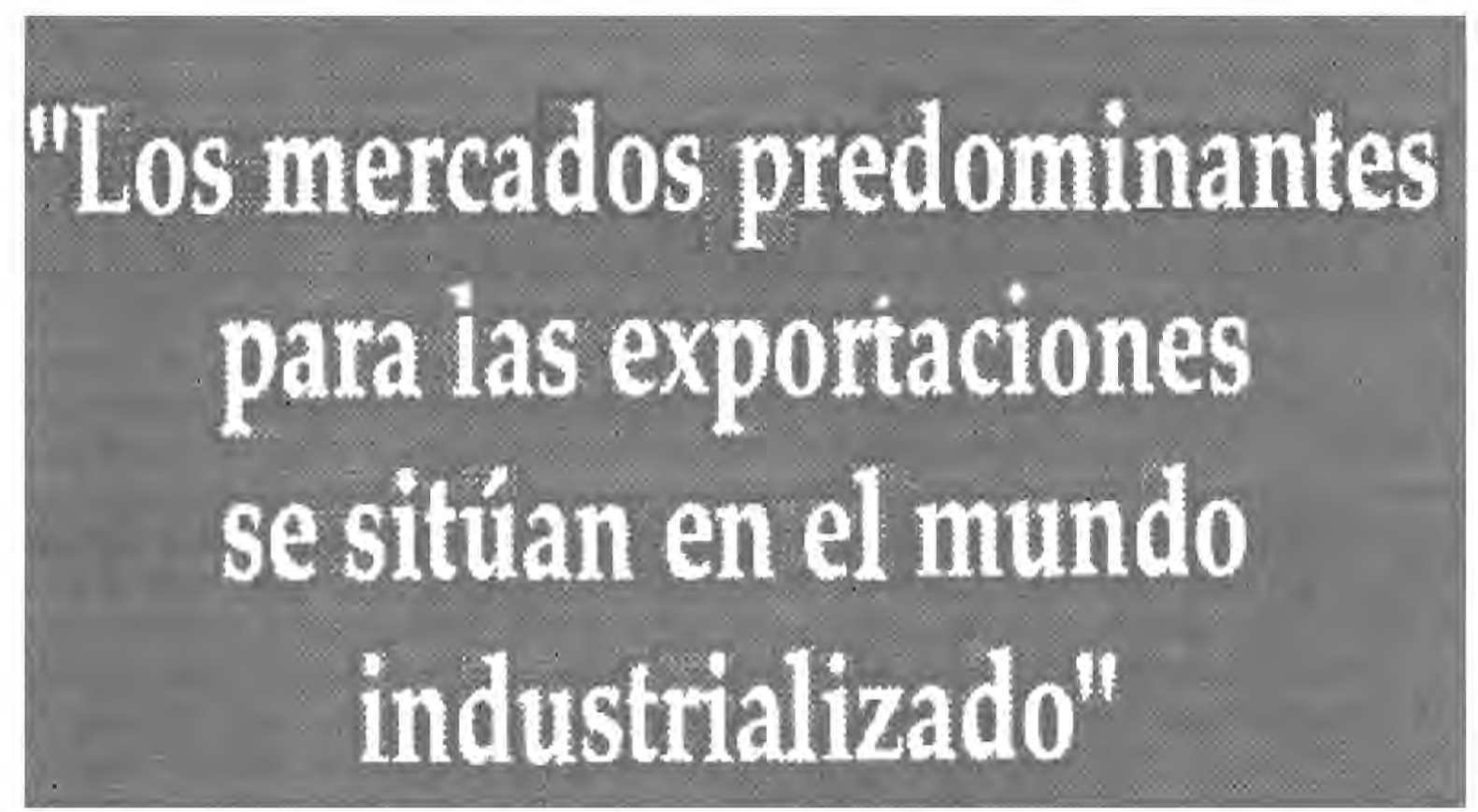


valor de las exportaciones de manufacturas de los países andinos, con excepción de Bolivia, se expandió en medida considerablemente mayor que el valor de las exportaciones totales; algo similar, aunque con menor intensidad en la mayoría de países, ocurrió con las semimanufacturas.

Entre 1987 y 1992 se produjo una generalizada mejoría del dinamismo exportador de las economías de los países del GRAN. En la totalidad de los casos, las manufacturas lideraron el avance, seguidos de las semimanufacturas.
En conclusión, el mayor dinamismo en las exportaciones manufactureras se ha convertido en un rasgode mediano plazo de las exportaciones del GRAN. Ello se encuentra en correspondencia con la tendencia global, pues en las dos últimas décadas el volumen del comercio mundial de manufacturas se ha incrementado dos veces más rápido que el de los productos básicos. En ese período se comprueba, además, si bien el comercio mundial de manufacturas creció a una tasa significativa, las exportaciones andinas de ese orígen crecieron a una tasa anual promedio mayor. Esto pone de relieve la im-

Cuadro 3

TASAS DE CRECIMIENTO ANUAL DE LOS VALORES EN DOLARES CORRIENTES (Porcentajes)

\begin{tabular}{|lrrr|}
\hline & $1970-1980$ & $1980-1982$ & $1987-1992$ \\
Bolivia & 19.1 & -4.9 & 0.0 \\
Productos primarios & 13.7 & -16.1 & 15.3 \\
Semimanufacturados & 5.5 & -11.90 & 54.9 \\
Bienes manufacturados & 16.3 & -8.2 & 6.0 \\
Total & & & \\
Colombia & 16.2 & 2.9 & 3.8 \\
Productos primarios & 23.0 & 5.6 & 3.7 \\
Semimanufacturados & 29.5 & 3.7 & 18.0 \\
Bienes manufacturados & 18.4 & 3.5 & 6.6 \\
Total & & & \\
Ecuador & 26.8 & -1.8 & 10.5 \\
Productos primarios & 44.2 & -6.7 & -11.2 \\
Semimanufacturados & 33.4 & -7.2 & 22.2 \\
Bienes manufacturados & 29.3 & -2.9 & 7.9 \\
Total & & & \\
Perú & & -8.6 & 5.9 \\
Productos primarios & 16.9 & -4.1 & 20.8 \\
Semimanufacturados & 6.6 & -5.4 & 19.5 \\
Bienes manufacturados & 46.8 & -2.9 & 7.9 \\
Total & 12.4 & & \\
Venezuela & & -10.4 & 4.6 \\
Productos primarios & 19.1 & -6.0 & 5.7 \\
Semimanufacturados & 21.0 & 14.2 & 17.4 \\
Bienes manufacturados & 25.0 & -8.2 & 5.8 \\
\hline Total & 19.7 & & \\
\hline
\end{tabular}

Fuenta: lod 